\title{
Strengthening of Vanadium Alloys by Internal Oxidation*
}

\author{
By M. Tokiwai** and S. Morozumi***
}

\begin{abstract}
Fundamental experiments on the internal oxidation process of vanadium alloys were performed for the purpose of improving the high temperature strength of vanadium alloys. The following results were obtained:

(1) Zirconium and silicon were alloyed to vanadium, respectively, as internally oxidizing elements. Zirconium was found to be more favorable than silicon because of the superior high-temperature strength of the internally oxidized $\mathrm{V}-\mathrm{Zr}$ alloy.

(2) An excess of oxygen, supplied by decomposition of $\mathrm{NiO}$, increased the amount of oxygen dissolved in solid-solution in the internally oxidized alloy, which caused strengthening of the alloys not at high temperature but at low temperature, accompanied by embrittlement.
\end{abstract}

(Received August 31, 1979)

\section{Introduction}

Vanadium is one of the refractory metals, of which strength, however, is not sufficient to permit its practical use as a high temperature material. The internal oxidation process for particle-dispersion-hardening is one of promising methods for improvement of the high temperature strength. The studies of internal oxidation phenomena and tensile properties in internally oxidized alloys of group $\mathrm{V}$ transition metals, niobium ${ }^{(1)(2)}$ and tantalum ${ }^{(3)}$, have been reported. In the case of vanadium alloys, a few investigations have been reported, e.g. the formation of dispersion phase at the surface layer of $\mathrm{V}-20 \mathrm{Ti}$ alloy during immersion in liquid sodium at $773-1073 \mathrm{~K}\left(500-800^{\circ} \mathrm{C}\right)^{(4)}$. However, no detailed studies have been carried out on vanadium alloys. Therefore, in this paper, fundamental experiments on the selection of the alloying element, internal oxidation conditions and the stability of dispersed particles were performed.

* This paper was originally published in Japanese in J. Japan Inst. Metals, 41 (1977), 1033.

** Graduate School, Tohoku University, Sendai, Japan. Currently, Central Research Institute of Electric Power Industry, Department of Atomic Energy, Komae-shi, Tokyo 182, Japan.

*** Research Institute for Iron, Steel and Other Metals, Tohoku University, Sendai 980, Japan.
First of all, a proper alloying element must be determined. The element should have such a property that the free energy of oxide formation is smaller (larger as the absolute value) than that of vanadium oxide and be internally oxidized by an appropriate internal oxidation process. Among such alloying elements, titanium satisfies the above condition and it is soluble in vanadium in all proportions. As vanadium has large solubility of oxygen, when $\mathrm{V}-\mathrm{Ti}$ alloy is internally-oxidized, the alloy will dissolve considerable amounts of titanium and oxygen in addition to dispersed oxide particles. Some metals have too low a boiling temperature to prepare the alloy and some other elements have too low a melting point of the oxide.

As a result of this screening process, Vsilicon and V-zirconium alloys were selected for this study. After an appropriate internal oxidation treatment, the microstructure and tensile properties of these alloys were investigated and compared. Then effects of the internal oxidation temperature, the oxidizing time and the quantity of alloying element, and the stability of oxide particles were studied especially in the $\mathrm{V}-\mathrm{Zr}$ alloy system, as well as the effect of excess oxygen in the V-Si alloy system. 


\section{Experimental}

\section{Samples}

As raw materials, $99.8 \%$ pure electro-flake vanadium, $99.9 \%$ pure sponge zirconium and $99.0 \%$ pure silicon were used. Alloy lumps were prepared by arc-melting in argon gas atmosphere, for $\mathrm{V}-\mathrm{Si}$ alloys silicon and vanadium flakes were directly mixed and arc melted, which for $\mathrm{V}-\mathrm{Zr}$ alloys, a mother alloy of $\mathrm{V}-10 \% \dagger \mathrm{Zr}$ previously prepared and the flake vanadium were mixed in exact proportions and were subsequently arc-melted. The alloy lumps were cut into an appropriate size and then rolled at room temperature to prepare two kinds of specimens: $0.1 \mathrm{~mm}$ thick foils for electron microscopy and $0.3 \mathrm{~mm}$ thick specimens with a gauge length of $22 \mathrm{~mm}$ and a width of $4 \mathrm{~mm}$ for the tensile test. Finally, shaped specimens were wrapped with zirconium foil and annealed at $1323 \mathrm{~K}\left(1070^{\circ} \mathrm{C}\right)$ for $3.6 \mathrm{Ks}$ in a vacuum of $4 \times$ $10^{-3} \mathrm{~Pa}$. The chemical compositions before the internal oxidation of the $\mathrm{V}-\mathrm{Zr}$ alloy specimens for tensile tests were $0.16,0.32$ and $1.95 \% \mathrm{Zr}$, with the following interstitial impurities in weight percent: C: $0.005-0.006$, O: $0.015-$ 0.018 , N: $0.001 \%$. Vickers hardness measurement also was made for arc melted lumps to know the alloying effect of zirconium.

\section{Internal oxidation}

It is very important to control the partial pressure of oxygen in the oxidizing atmosphere, because vanadium has a high solubility of oxygen. In the case of tantalum alloys ${ }^{(3)}$ and niobium alloys ${ }^{(1)}$, internal oxidation was performed in a vacuum of $1.3-2.6 \times 10^{-3} \mathrm{~Pa}$ at $1273 \mathrm{~K}\left(1000^{\circ} \mathrm{C}\right)$.

In this study, an improved Rhines method ${ }^{(5)}$ was used. Rhines embedded the specimen directly into the powder of the oxygen sources. In the present experiment, however, as shown in Fig. 1, there are two compartments in the silica tube: One is the specimen room which is set at a suitable temperature for internal oxida-

$\dagger$ The composition is expressed in weight percent throughout the paper. tion and the other is the oxygen source room at another suitable temperature for decomposition of oxygen sources and keeping the atmosphere under a given partial pressure of oxygen. Several kinds of oxide powder, i.e. $\mathrm{Fe}_{2} \mathrm{O}_{3}$, $\mathrm{Cr}_{2} \mathrm{O}_{3}$, etc. were tentatively tested as the oxygen source and $\mathrm{NiO}$ was found to be the best of them. The standard amount of NiO, for example, in the case of $\mathrm{V}-\mathrm{Zr}$ alloys, was determined in such a way that an optimum amount of oxygen for oxidizing whole zirconium atoms in the alloy into $\mathrm{ZrO}_{2}$ can be supplied.

In reference to the diagram of free energy of formation $^{(6)}$ of the oxide, the partial pressure of oxygen by decomposition of $\mathrm{NiO}$ is lower than that required for the formation of VO. At the same time, the partial pressure of oxygen is kept higher than the equilibrium pressure of the internally oxidized element.

Under such conditions, the internal oxidation temperature was varied. As shown in Fig. 1, specimens were surrounded with silica pieces so that the oxygen generated by decomposition of $\mathrm{NiO}$, do not collide directly with them.

\section{Testing method}

Foils for electron microscopy were prepared through a combination of polishing techniques as follows; chemical polishing by dilute nitric acid (at about $293 \mathrm{~K}$ ), jet polishing by sulfuric acid plus methyl alcohol, and electrochemical polishing by sulfuric acid plus methyl alcohol with current density $10-30 \mathrm{kA} / \mathrm{m}^{2}$ at $278-281 \mathrm{~K}$. Then the foils were observed with JEM-6A operating at $100 \mathrm{kV}$. In the tensile testing, an Instron machine was used and the specimen was wrapped with the zirconium foil in a vacuum of $1.33 \mathrm{~Pa}$. Initial strain rate was $4-11 \times 10^{-5} \mathrm{~s}^{-1}$. The hardness test was performed by a microvickers hardness tester with

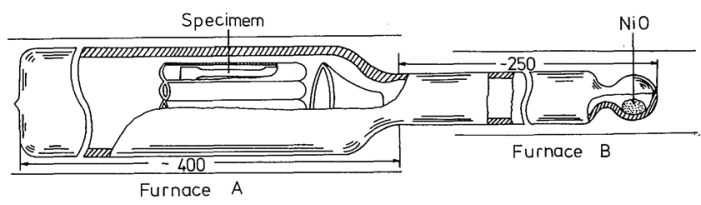

Fig. 1 Schematic of silicaware of internal oxidation: Furnaces A and B are kept at different temperatures, respectively. 
a load of $1.96 \mathrm{~N}$.

\section{Experimental Results}

\section{Selection of alloys}

The results of tensile tests at the temperature range from room temperature to $1073 \mathrm{~K}\left(800^{\circ} \mathrm{C}\right)$ for $\mathrm{V}-0.32 \mathrm{Zr}$ and $\mathrm{V}-0.50 \mathrm{Si}$ alloys, which were internally oxidized at $1173 \mathrm{~K}\left(900^{\circ} \mathrm{C}\right)$ for $21.6 \mathrm{ks}$ are shown in Fig. 2. Although the strength of $\mathrm{V}-0.32 \mathrm{Zr}$ is lower at room temperature, it becomes higher above $473 \mathrm{~K}\left(200^{\circ} \mathrm{C}\right)$ than that of $\mathrm{V}-0.50 \mathrm{Si}$, and the relatively high strength of $\mathrm{V}-0.32 \mathrm{Zr}$ is kept over the high temperature range. The uniform elongation of $\mathrm{V}-0.32 \mathrm{Zr}$ decreases at $673-773 \mathrm{~K}\left(400-500^{\circ} \mathrm{C}\right)$ where the maximum strength is observed, while above $873 \mathrm{~K}\left(600^{\circ} \mathrm{C}\right)$ it increases and becomes larger than that of $\mathrm{V}-0.50 \mathrm{Si}$. This difference in strength between $\mathrm{V}-0.32 \mathrm{Zr}$ and $\mathrm{V}-0.50 \mathrm{Si}$ alloys in the high temperature region is examined by electromicroscopy. Photograph 1 shows the microstructure of $\mathrm{V}-0.50 \mathrm{Si}$ alloy internally oxidized at $1173 \mathrm{~K}\left(900^{\circ} \mathrm{C}\right)$ for $1.02 \mathrm{ks}$. In this photograph, dispersed oxide particles in the matrix and precipitate-free zone (PFZ) along grain boundaries can be seen. On the other hand, such PFZ is scarcely observed in V-0.32 Zr alloy, as shown in Photo. 2. As will be discussed later, in every specimen the

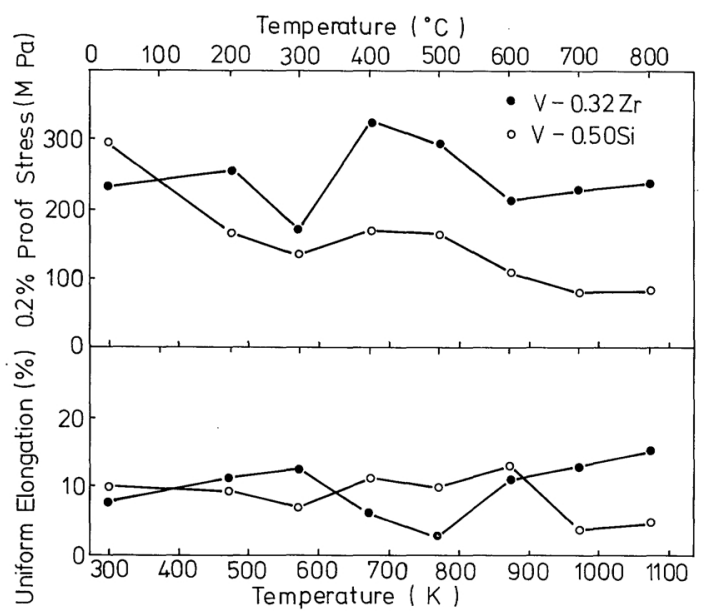

Fig. 2 Temperature dependence of $0.2 \%$ proof stress and uniform elongation in internally oxidized $\mathrm{V}-0.32 \mathrm{wt} \% \mathrm{Zr}$ and $\mathrm{V}-0.5 \%$ Si alloys.

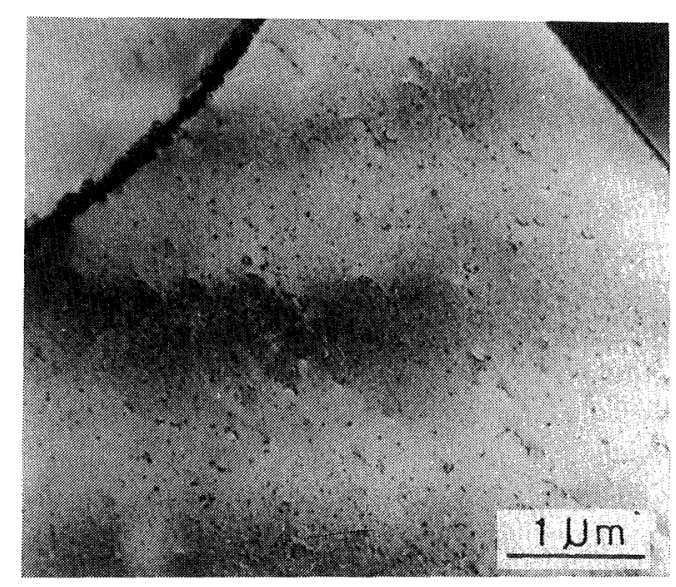

Photo. 1 Electron micrograph of a V-0.5 wt\% Si alloy, internally oxidized at $1173 \mathrm{~K}\left(900^{\circ} \mathrm{C}\right)$ for $1.02 \mathrm{ks}$.



Photo. 2 Electron micrograph of a $\mathrm{V}-0.32 \mathrm{wt} \% \mathrm{Zr}$ alloy, internally oxidized at $1173 \mathrm{~K}\left(900^{\circ} \mathrm{C}\right)$ for $1.02 \mathrm{ks}$.

preferential precipitation takes place on dislocations.

The high temperature strength is believed to be so effectively influenced by the grain boundary sliding that may be higher in $\mathrm{V}-0.32 \mathrm{Zr}$, in which the width of PFZ is narrower, than in V-0.50 Si alloy.

\section{Influence of the supplied oxygen}

Figure 3 shows the effect of excess oxygen on the $0.2 \%$ proof stress in $\mathrm{V}-0.50 \mathrm{Si}$ alloy, internally oxidized at $1203 \mathrm{~K}\left(930^{\circ} \mathrm{C}\right)$ for $118.8 \mathrm{ks}$. 


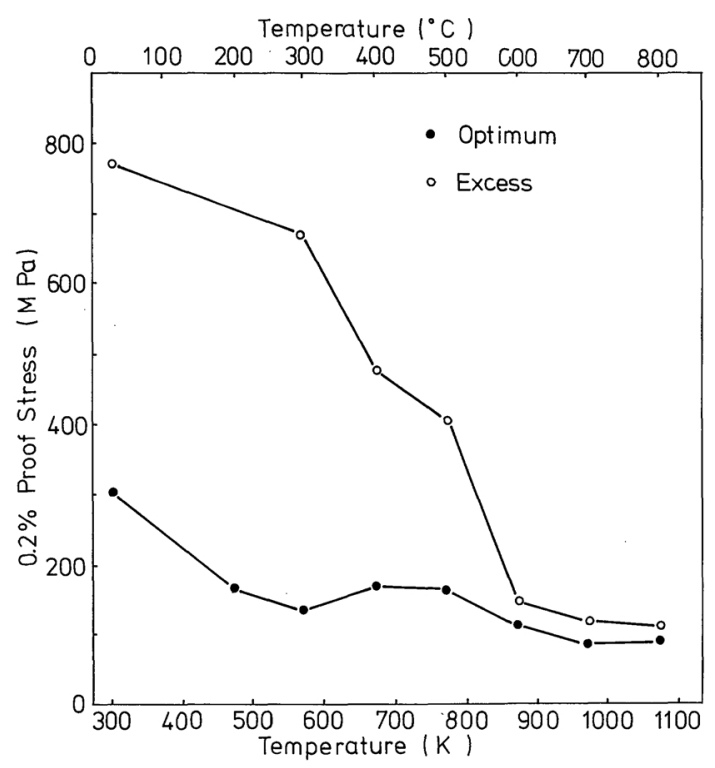

Fig. 3 Temperature dependence of $0.2 \%$ proof stress in $\mathrm{V}-0.5 \% \mathrm{Si}$ alloy specimens, internally oxidized with an optimum and an excess amount of oxygen, respectively.

Specimen $\mathrm{A}(\bullet)$ was supplied with just enough amount of oxygen to form completely $\mathrm{SiO}_{2}$, while Specimen B $(O)$ was with three times as much oxygen. Because specimen B $(\bigcirc)$ contains a large amount of oxygen in solution, in addition to dispersed oxide particles, it shows considerably high strength up to about $773 \mathrm{~K}$ $\left(500^{\circ} \mathrm{C}\right)$. At temperature above $873 \mathrm{~K}\left(600^{\circ} \mathrm{C}\right)$, however, the effect of excess oxygen is not noticeable. This indicates that this alloy is not useful as high temperature materials. Moreover, the embrittlement of this alloy that occurs at relatively low temperatures, including room temperature, is a serious problem in practical use. A similar effect of excess oxygen is observed in $\mathrm{V}-\mathrm{Zr}$ alloys.

\section{Effect of the quantity of the alloying element}

In $\mathrm{V}-\mathrm{Zr}$ alloys, before internal oxidation, the effect of the zirconium content on the properties of alloys was investigated. In electron microscope observation, some compounds can be seen in a $\mathrm{V}-0.32 \mathrm{Zr}$ alloy. This may be ascribed to the facts that in the case of $0.32 \% \mathrm{Zr}$ in vanadium, $\mathrm{V}-\mathrm{Zr}$ intermetallic compounds are formed by the metallurgical reaction and/or

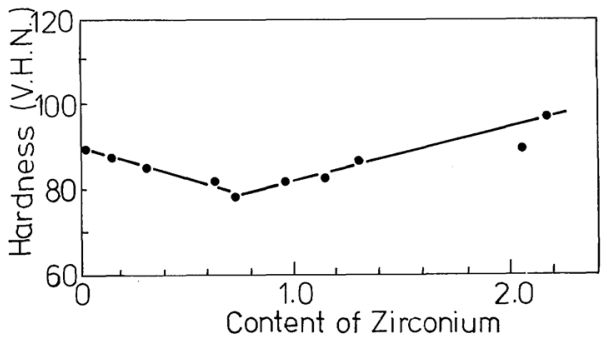

Fig. 4 Variation of Vickers hardness of vanadium with zirconium content.

the scavenging effect of zirconium, which preferentially combines with oxygen and other interstitial impurity atoms, will decrease the strength of vanadium.

The result of hardness test as to the scavenging effect is shown in Fig. 4, in which the hardness reaches a minimum value at $0.8 \% \mathrm{Zr}$. It is obvious, therefore, that the scavenging effect takes place in $\mathrm{V}-\mathrm{Zr}$ alloy. According to the result of Rostoker ${ }^{(7)}$, it has been reported that the zirconium addition corresponding to the minimum value in hardness was about $4 \%$, which is very different from the present result. This disparity may be attributed to the difference in the purity (especially interstitial impurity) of vanadium metal used. It would not be expected that the addition of more amount of zirconium than that required for scavenging might improve the properties of the alloy. For example, in a V-1.95 $\mathrm{Zr}$ alloy, the proof stress at room temperature is about $265 \mathrm{MPa}$ and the ultimate tensile strength and the elongation are about $402 \mathrm{MPa}$ and $10 \%$, respectively. These tensile properties are just comparable to those of $\mathrm{V}-0.32 \mathrm{Zr}$ alloy. Photograph 3 shows the result of the electron probe X-ray microanalysis, indicating qualitative changes through the inclusion (labeled A) and the matrix in the specimen before the internal oxidation treatment. In the inclusion, contents of oxygen and vanadium are lower, but zirconium is higher, than those in the matrix. From this fact, this inclusion is very likely to be a $\mathrm{Zr}-\mathrm{V}$ compound. Therefore, even the addition of approximately $1 \%$ zirconium can saturate the solid solution of zirconium in the matrix and cause the formation of the second phase. Hence, it is clear that a larger addition of zirconium is not effective in 




Photo. 3 EPMA of the zirconium-rich particle (A) for $\mathrm{Zr}-\mathbf{L} \alpha, \mathrm{V}-\mathbf{L} \alpha$ and $\mathrm{O}-\mathrm{K} \alpha$ lines in a $\mathrm{V}-0.98 \% \mathrm{Zr}$ alloy.

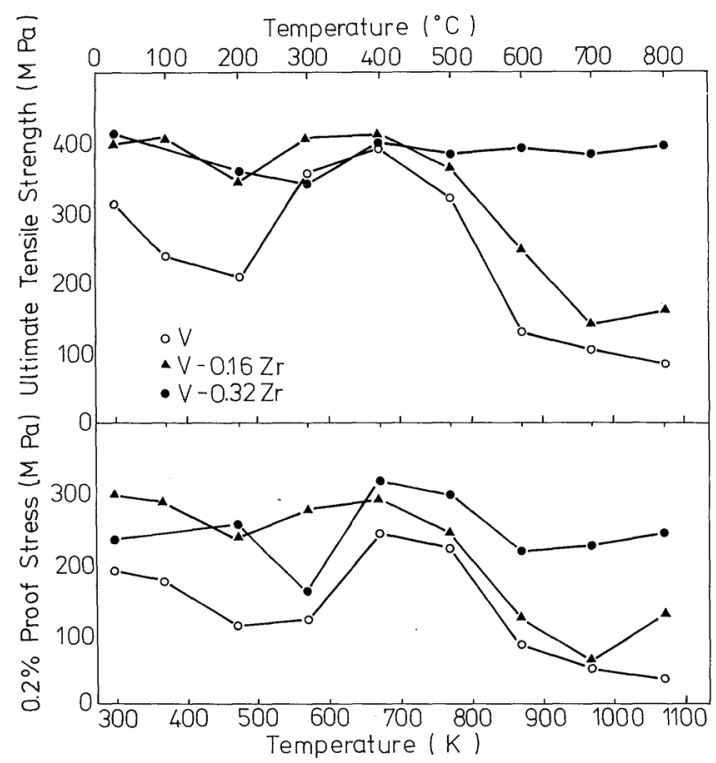

Fig. 5 Temperature dependence of tensile strength of vanadium, internally-oxidized $\mathrm{V}-0.16$ and $\mathrm{V}-$ $0.32 \% \mathrm{Zr}$ alloys.

the internally oxidized alloys.

On the other hand, the addition of less than $0.32 \%$ zirconium (e.g., in the case of $0.16 \% \mathrm{Zr}$ addition as shown in Fig. 5 the strength above $873 \mathrm{~K}\left(600^{\circ} \mathrm{C}\right)$ of an internally oxidized specimen is nearly equal to that of pure vanadium and lower than that of $\mathrm{V}-0.32 \mathrm{Zr}$ alloy. From this result, it may be concluded that the proper range of zirconium content in $\mathrm{V}-\mathrm{Zr}$ alloys for internal oxidation is 0.3 to $1.0 \%$.

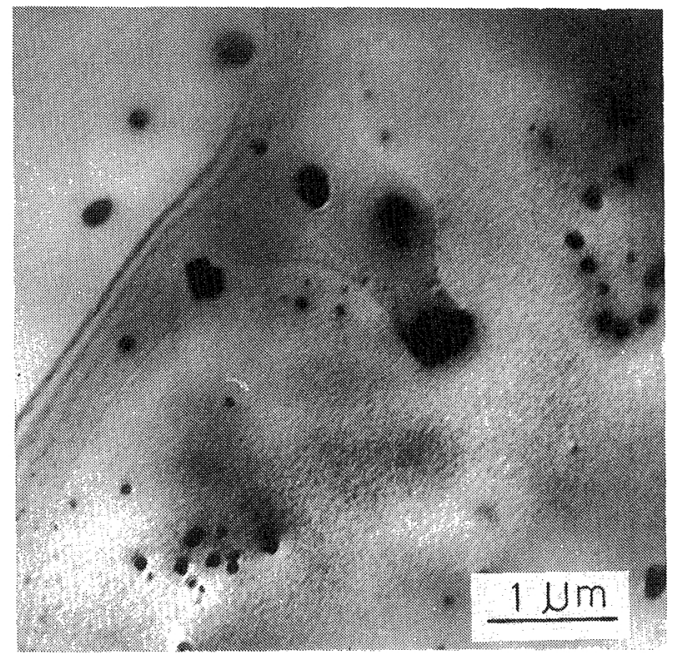

Photo. 4 Electron micrograph of a $\mathrm{V}-0.32 \% \mathrm{Zr}$ alloy, before internal oxidization.

\section{The effect of the internal oxidation temperature}

The microstructure of internally oxidized $\mathrm{V}-\mathrm{Zr}$ alloys is influenced by the heat treatment temperature and/or time. The degree of influence shows greater dependance on the temperature than on the time.

Photograph 4 shows the microstructure of $\mathrm{V}-0.64 \% \mathrm{Zr}$ before internal oxidation. As mentioned above, some large inclusions, which are believed to be a zirconium compound, are observed, but the internally oxidized particles are hardly observable. When the alloy is internally oxidized at above $923 \mathrm{~K}\left(750^{\circ} \mathrm{C}\right)$, there is a clear tendency of preferential precipitation on dislocations. This effect can be observed in Photos. 5 and 6. By elevating the treatment temperature, the internally oxidized particles become coaser and distribute homogeneously (Photo. 7). As shown in Photo. 8, however, when the treatment temperature is further raised, both the thickening of oxide particles and the formation of PFZ along dislocations take place. From these microstructural changes, the optimum temperature for this alloy to internally oxidize is at about $1273 \mathrm{~K}\left(1000^{\circ} \mathrm{C}\right)$ or below.

With the aid of electron microscope observation, the dependence of tensile properties upon the internal oxidation temperature in a V- 


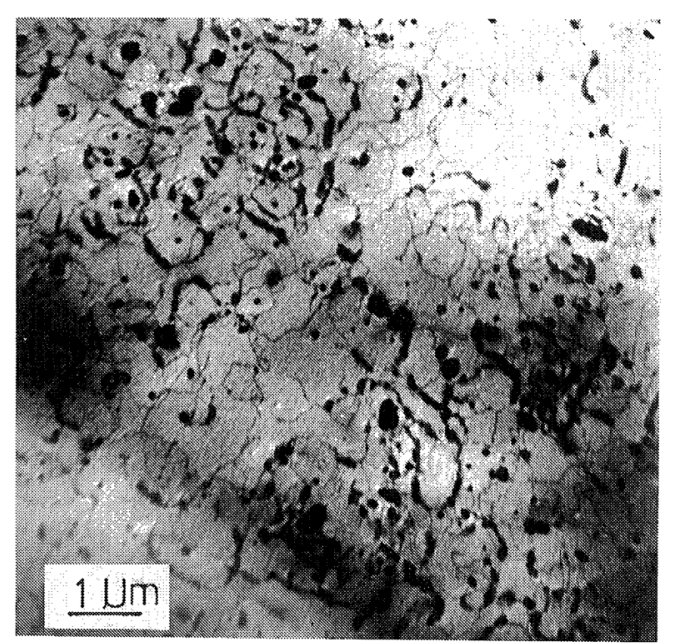

Photo. 5 Electron micrograph of a $\mathrm{V}-0.32 \% \mathrm{Zr}$ alloy, internally oxidized at $1033 \mathrm{~K}\left(760^{\circ} \mathrm{C}\right)$ for $1.8 \mathrm{ks}$.

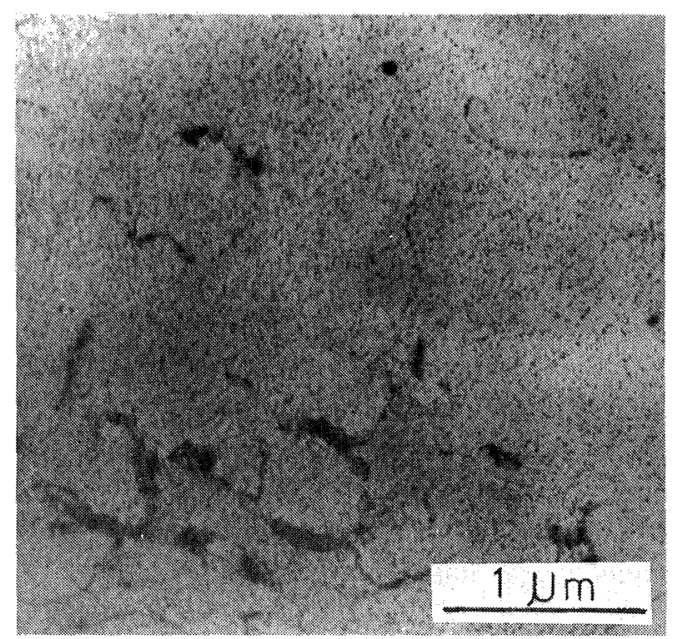

Photo. 6 Electron micrograph of a $\mathrm{V}-0.32 \% \mathrm{Zr}$ alloy, internally oxidized at $1123 \mathrm{~K}\left(850^{\circ} \mathrm{C}\right)$ for $1.8 \mathrm{ks}$.

$0.32 \mathrm{Zr}$ alloy was investigated. The alloy composition is within the proper zirconium content for internal oxidation. For the tensile specimen, it is necessary to be oxidized for a longer time than that of thin foils for electron microscopy, in order to be completely internally-oxidized through whole the specimen. The treatment time was calculated from the following equation:

$$
d / 2=(4 D t)^{1 / 2}
$$

where $d$ is the thickness of specimen, $D$ is the diffusion constant of oxygen in vanadium, and

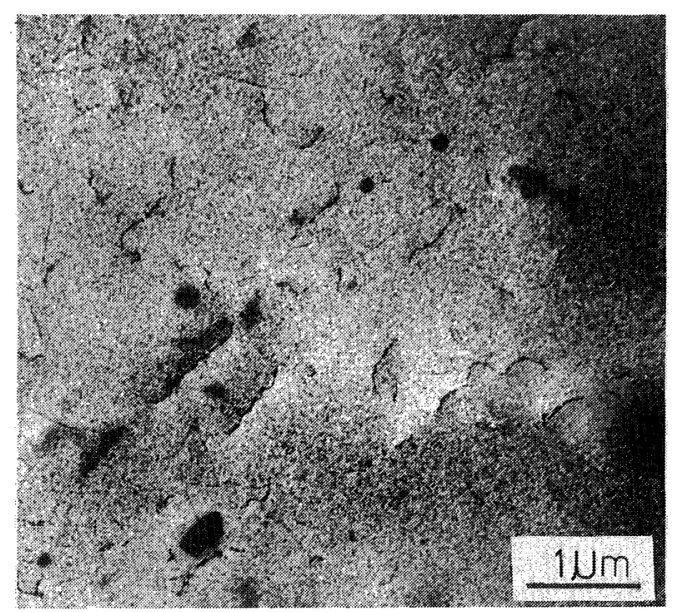

Photo. 7 Electron micrograph of a $\mathrm{V}-0.32 \% \mathrm{Zr}$ alloy, internally oxidized at $1273 \mathrm{~K}\left(1000^{\circ} \mathrm{C}\right)$ for $1.8 \mathrm{ks}$.

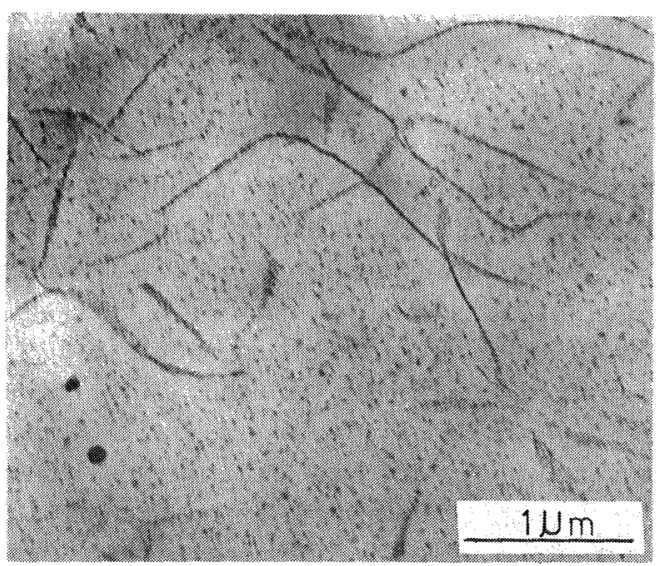

Photo. 8 Electron micrograph of a $\mathrm{V}-0.32 \% \mathrm{Zr}$ alloy, internally oxidized at $1323 \mathrm{~K}\left(1050^{\circ} \mathrm{C}\right)$ for $3.6 \mathrm{ks}$.

$t$ is the internal oxidation time. The value used for $D$ was $1.3 \times 10^{-6} \exp (-29000 / R T) \mathrm{m}^{2} / \mathrm{s}$, which was proposed by Doyle ${ }^{(8)}$. As the result of calculation, the internal oxidation conditions were set up at $1173 \mathrm{~K}\left(900^{\circ} \mathrm{C}\right)$ for $36 \mathrm{ks}$, $1273 \mathrm{~K}\left(1000^{\circ} \mathrm{C}\right)$ for $21.6 \mathrm{ks}, 1323 \mathrm{~K}\left(1050^{\circ} \mathrm{C}\right)$ for $10.8 \mathrm{ks}, 1373 \mathrm{~K}\left(1100^{\circ} \mathrm{C}\right)$ for $9.0 \mathrm{ks}$, and $1473 \mathrm{~K}\left(1200^{\circ} \mathrm{C}\right)$ for $7.2 \mathrm{ks}$. Specimens internally oxidized under the above conditions were tensile tested at room temperature and $1073 \mathrm{~K}$ $\left(800^{\circ} \mathrm{C}\right)$.

The result on the $0.2 \%$ proof stress is shown in Fig. 6, in which the specimen internallyoxidized at $1323 \mathrm{~K}\left(1050^{\circ} \mathrm{C}\right)$ has higher strength than those of specimens oxidized below or 


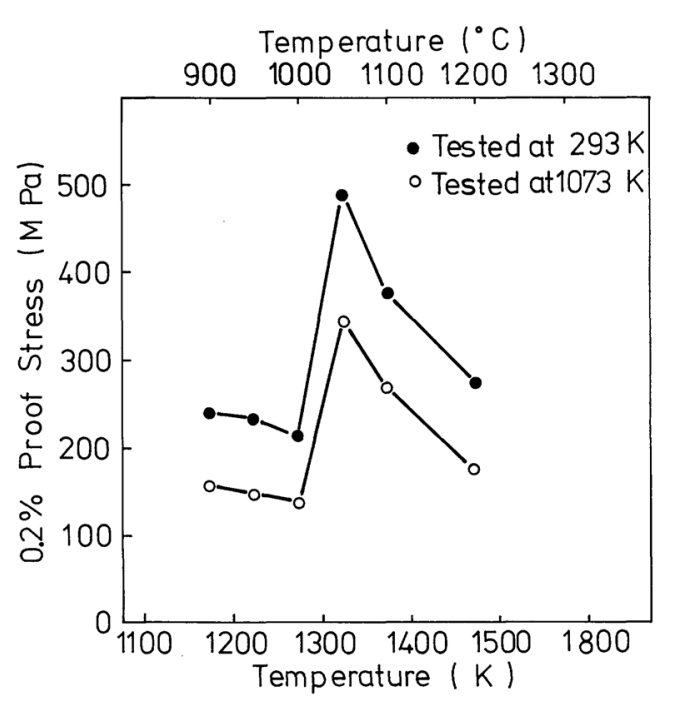

Fig. 6 Effect of internal oxidation temperature on $0.2 \%$ proof stress of an internally-oxidized $\mathrm{V}-$ $0.32 \% \mathrm{Zr}$ alloy.

above $1323 \mathrm{~K}\left(1050^{\circ} \mathrm{C}\right)$. This temperature dependence of the strength may be explained by considering the expansion of $\mathrm{ZrO}_{2}$, as will be discussed in Section IV.

In order to use these experimental results to improve the strength of the alloy, about $1273 \mathrm{~K}\left(1000^{\circ} \mathrm{C}\right)$ is recommended as a suitable temperature for internal oxidation. However, with regard to the simple dispersion of oxide particles, it may by sufficient to investigate specimens internally oxidized below this temperature. As specimens oxidized at 1173$1273 \mathrm{~K}\left(900-1000^{\circ} \mathrm{C}\right)$ have approximately the same level of strength, fluctuations of the internal oxidation temperature in this temperature range may have little effect on the strength.

\section{The influence of internal oxidation time}

In the previous section, the oxidation time was established by calculating the diffusion constant of oxygen in vanadium. The propriety of this procedure is substantiated by the following experiment.

The internal oxidation zone is formed on the surface of specimen. The thickness of the internally oxidized zone increases parabolically with increase in oxidation time (Fig. 7). The strength of the specimen, therefore, will in-

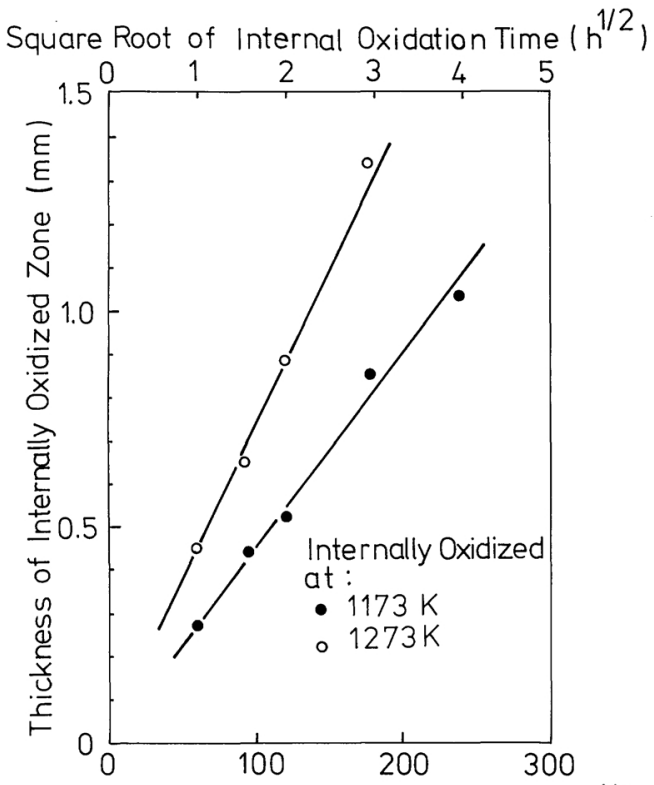

Square Root of Internal Oxidation Time ( $s^{1 / 2}$ )

Fig. 7 Relation between the square root of internal oxidation time and the thickness of the internallyoxidized zone in $\mathrm{V}-0.32 \% \mathrm{Zr}$ alloy specimens, internally oxidized at $1173 \mathrm{~K}\left(900^{\circ} \mathrm{C}\right)$ and $1273 \mathrm{~K}$ $\left(1000^{\circ} \mathrm{C}\right)$, respectively.

crease until the initial oxidation front reaches the center of the thickness. In the case of the initial oxidation at a given temperature, the result of measuring the variation in strength with the oxidation time will give a simple criterion for determining the time required for the saturation of the increase in strength.

Figure 8 shows the change in proof stress at room temperature in a $\mathrm{V}-0.32 \mathrm{Zr}$ alloy internally oxidized at $1323 \mathrm{~K}\left(1050^{\circ} \mathrm{C}\right)$ with varying oxidation time. In the case of this alloy, the strength becomes constant after about $3 \mathrm{~h}$. Even when the internal oxidation treatment is performed for a long time at $1323 \mathrm{~K}\left(1050^{\circ}\right.$ C), the strength does not decrease. This may indicate oxide particles thus formed are very stable at the temperature.

\section{Stability of oxide particles}

In order to investigate the stability of oxide particles, heat treatments at $1573 \mathrm{~K}\left(1300^{\circ} \mathrm{C}\right)$ for $10.8,36.0$, and $72.0 \mathrm{ks}$ intervals in a vacuum of $2.67 \times 10^{-4} \mathrm{~Pa}$ were performed for a V- 


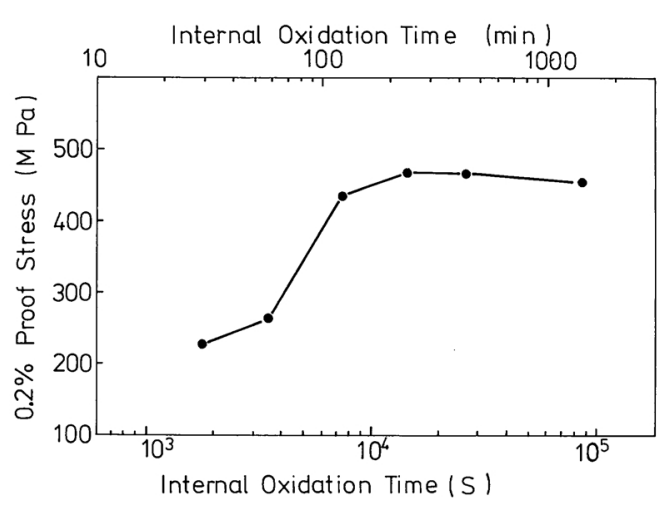

Fig. 8 Effect of internal oxidation time on $0.2 \%$ proof stress of an internally-oxidized $\mathrm{V}-0.32 \% \mathrm{Zr}$ alloy.

$0.32 \mathrm{Zr}$ alloy internally-oxidized at $1273 \mathrm{~K}$ $\left(1000^{\circ} \mathrm{C}\right)$ for $1.5 \mathrm{ks}$. According to Seybolt ${ }^{(1)}$, such growth of particles in many alloy systems follows:

$$
d^{3}-d_{0}^{3}=K t
$$

where $d_{0}$ and $d$ are the particle radii at the starting point and at time $t$ at a given temperature, respectively, and $K$ is a constant that is to be determined by the interface energy between particle and matrix, diffusion constant, solubility, molar fraction of particles and the temperature. In this equation, measuring the particle radius heated for each temperature, the radius has a linear relationship with respect to the holding time.

On the other hand, according to Fullman ${ }^{(10)}$, the particle radius, $r$, is determined by the following equation:

$$
(d / 3)^{3}=(3 f) /(4 \pi N) \text { or } d^{3} \propto 1 / N
$$

where $f$ is the volume fraction and $N$ is the number of particles in unit volume. In this experiment, $1 / N$ was measured instead of $d^{3}$. Figure 9 shows the relation of $1 / N$ to holding time, which is in good agreement with Seybolt's relation, except at $t=0$, where the measured value deviates from the line. This deviation may be attributable to the fact that it is not always accurate to plot the measured value in the specimen internally-oxidized at $1273 \mathrm{~K}$ $\left(1000^{\circ} \mathrm{C}\right)$ as the starting point of the particle growth at $1573 \mathrm{~K}\left(1300^{\circ} \mathrm{C}\right)$. But the growth

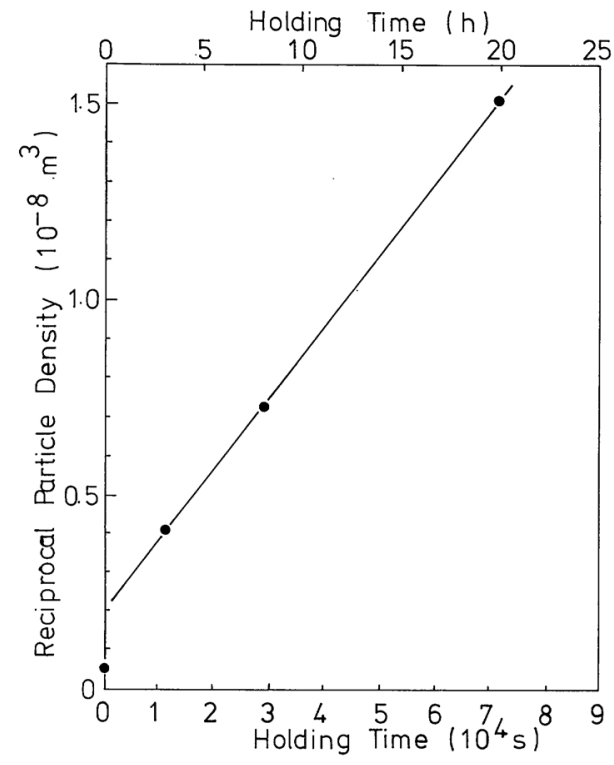

Fig. 9 Change in the reciprocal particle density in a $\mathrm{V}-0.32 \% \mathrm{Zr}$ alloy, internally oxidized at $1273 \mathrm{~K}$ $\left(1000^{\circ} \mathrm{C}\right)$, with holding time at $1573 \mathrm{~K}\left(1300^{\circ} \mathrm{C}\right)$.

becomes steady after holding the specimen for some time at $1573 \mathrm{~K}\left(1300^{\circ} \mathrm{C}\right)$. Therefore, in the steady state region, the particle growth rate shows good linearity.

In order to investigate the resolution of oxide particles at higher temperatures, the specimen oxidized at $1273 \mathrm{~K}\left(1000^{\circ} \mathrm{C}\right)$ was heated at $1737 \mathrm{~K}\left(1500^{\circ} \mathrm{C}\right)$ for $36 \mathrm{ks}$ in a vacuum of $2.67 \times 10^{-4} \mathrm{~Pa}$. The microstructure of the specimen is shown in Photo. 9 where no coarse particles can be seen. The fine oxide particles become finer and the density decreases. This indicates that the solubility of $\mathrm{ZrO}_{2}$ into the matrix (as in the $\mathrm{Nb}-\mathrm{Zr}-\mathrm{O}$ system $^{(11)}$ ), increases at higher temperatures and precipitation does not take place during cooling because of the rapid cooling rate. In order to clarify this fact, the specimen mentioned above was rapidly cooled in argon flow after heating at $1873 \mathrm{~K}$ $\left(1600^{\circ} \mathrm{C}\right)$ for $7.2 \mathrm{ks}$ and subsequently tempered at temperatures ranging from $873 \mathrm{~K}\left(600^{\circ} \mathrm{C}\right)$ to $1273 \mathrm{~K}\left(1000^{\circ} \mathrm{C}\right)$ for $3.6 \mathrm{ks}$.

As a result of this experiment, the hardness increased from $\mathrm{Hv} 120$ to $\mathrm{Hv} 200$ after tempering at $973 \mathrm{~K}\left(700^{\circ} \mathrm{C}\right)$ to $1073 \mathrm{~K}\left(800^{\circ} \mathrm{C}\right)$. This increase in hardness may imply the precipitation of $\mathrm{ZrO}_{2}$ during the heat treatment. 




Photo. 9 Electron micrograph of a V-0.32\% Zr alloy, internally oxidized at $1273 \mathrm{~K}\left(1000^{\circ} \mathrm{C}\right)$ for $1.5 \mathrm{Ks}$ and subsequently annealed at $1773 \mathrm{~K}\left(1500^{\circ} \mathrm{C}\right)$ for $0.6 \mathrm{ks}$.

\section{Discussion}

The objective of this experiment was to establish the fundamental conditions necessary for internal oxidation of $\mathrm{V}-\mathrm{Zr}$ alloys containing appropriate amounts of zirconium, and to measure the mechanical properties of the resultant alloys. The hardening phenomenon, attributable to the transformation of $\mathrm{ZrO}_{2}$ formed by the internal oxidation process, was found by varying the oxidation temperature. As shown in Fig. 6, it has been made clear that specimens internally oxidized at above $1323 \mathrm{~K}$ $\left(1050^{\circ} \mathrm{C}\right)$, have higher strength both at room temperature and $1073 \mathrm{~K}\left(800^{\circ} \mathrm{C}\right)$ than those oxidized below $1323 \mathrm{~K}\left(1050^{\circ} \mathrm{C}\right)$. The following text discusses this phenomenon.

First of all, there is a possibility that the hardening phenomenon in the specimen internally-oxidized at $1323 \mathrm{~K}\left(1050^{\circ} \mathrm{C}\right)$ is caused by the excess soluble oxygen due to decomposition of the silica tube and pieces. However, the results of tensile tests discussed in Section III2 clearly indicated that there was a great improvement in strength at $1073 \mathrm{~K}\left(800^{\circ} \mathrm{C}\right)$, so that the possibility mentioned above is not an adequate explanation.

Considering the thermal properties of $\mathrm{ZrO}_{2}$, there is a transformation point between $1253 \mathrm{~K}\left(980^{\circ} \mathrm{C}\right)$ and $1373 \mathrm{~K}\left(1100^{\circ} \mathrm{C}\right)$. When the transformation from a stable phase $\beta$ (tetragonal) to a lower temperature stable phase $\alpha$ (monoclinic) takes places, the density decreases from $6.10 \times 10^{3}$ to $5.68 \times 10^{3} \mathrm{~kg} / \mathrm{m}^{3}$, a volume increase of about $7.38 \%$. The thermal expansion coefficient of $\alpha$ phase is approximately the same as vanadium, so that the strain resulting from the transformation will remain at lower temperatures and the matrix around $\mathrm{ZrO}_{2}$ particles will be compressively strained by the rapid cooling from a high temperature. This compressive strain will increase the effective radius of the particles, that is the effective interparticle distance will decrease, and then the strength of the alloy will be increased. In this transformation process, the amount of strengthening depends on the width of the region relating to the relief process of the strain field, and on whether or not dislocations are generated in the process. With respect to such dislocation generation around inclusions in metals, relatively detailed calculations and observations have been reported in relation to the difference of the thermal expansion coefficient between the matrix and the inclusions ${ }^{(12)(13)}$. The stress relief near the $\mathrm{ZrO}_{2}$ particles will be discussed below.

Shear stress, $\tau_{\max }$, which is induced by the volume change due to the transformation of the $\mathrm{ZrO}_{2}$ phase, is expressed in the following formula:

$$
\tau_{\max }=3 \mu(r / R)^{3} \varepsilon
$$

where $\mu$ and $r$ are the shear modulus and particle radius, $R$ is the distance from the center of the particle and $R>r$ and $\varepsilon$ is the strain around the particle to be relieved.

The transformation of $\beta \rightleftarrows \alpha$ results in an about $7.38 \%$ volume increase, so that onedimensional expansion approaches $2.46 \%$. As the mean radius is about $25 \mathrm{~nm}$, the calculated displacement at the surface of the particles will be about $0.615 \mathrm{~nm}$ in the radial direction.

If this displacement is relieved at $R \simeq r$, $\tau_{\max } \simeq \mu / 14$, then $\tau_{\max }$ will exceed the stress required for dislocation generation, say $\mu / 47^{(3)}$, and dislocations will generate around the inclusions. If the stress relief takes place in the region 
of $R \simeq 2 r, \tau_{\max }$ reaches approximately $\tau_{\max } \simeq \mu /$ 108 and results in no dislocation generation. In fact, dislocations by the strain contrast induced by elastic strain are not seen around the inclusions. The stress induced by the transformation of $\mathrm{ZrO}_{2}$ can be relieved by the formation of elastic strain fields, and the effective particle radius seems to increase. However, the size of the elastic strain field and the effective radius induced by the transformation of $\mathrm{ZrO}_{2}$ are variable in the history of heat treatments of the post-internal oxidation process. Therefore, the following additional experiments were performed.

The V-0.32\% $\mathrm{Zr}$ specimens internally oxidized at $1343 \mathrm{~K}\left(1070^{\circ} \mathrm{C}\right)$ for $9.0 \mathrm{ks}$ were:

1. rapid cooled;

2. held at $1243 \mathrm{~K}\left(970^{\circ} \mathrm{C}\right)$ for $14.4 \mathrm{ks}$ and subsequently rapid cooled;

3. held at $1243 \mathrm{~K}\left(970^{\circ} \mathrm{C}\right)$ for $14.4 \mathrm{ks}$ and subsequently furnace cooled;

4. held at $1243 \mathrm{~K}\left(970^{\circ} \mathrm{C}\right)$ for $14.4 \mathrm{ks}$ and subsequently elevated temperature at $1373 \mathrm{~K}\left(1100^{\circ} \mathrm{C}\right)$ for $1.8 \mathrm{ks}$ (above the transformation temperature) and rapid cooled;

5. held at $1173 \mathrm{~K}\left(900^{\circ} \mathrm{C}\right)$ for $36 \mathrm{ks}$ and subsequently furnace cooled, respectively.

Then tensile tests were carried out on the specimens. The values of $0.2 \%$ proof stress obtained are as follows:

1. $429.5 \mathrm{MPa}$;

2. $367.8 \mathrm{MPa}$;

3. $343.2 \mathrm{MPa}$;

4. $446.2 \mathrm{MPa}$; and

5. $276.6 \mathrm{MPa}$, respectively.

From these values, it can be seen that the $0.2 \%$ proof stress of the specimens ( 1 and 4 ), of which final holding temperature is higher than the transformation temperature is relatively higher than that of the specimens $(2,3$ and 5) finally held below the transformation temperature. At the same time, the specimens rapidly cooled seem to have relatively higher strength than those furnace-cooled. These results, therefore, suggest that the behavior of the transformation of $\mathrm{ZrO}_{2}$ effectively influences the strength of this alloy.

\section{Conclusion}

In this study, with the objective of improving the high temperature strength of vanadium alloys, fundamental experiments on the internal oxidation process were performed. The main results are as follows.

(1) For use as the internal oxidized element, zirconium and silicon were investigated. The results showed that $\mathrm{V}-\mathrm{Zr}$ alloys have higher high-temperature strength than V-Si alloys, in the internally oxidized condition.

(2) The supply of excess oxygen in the internal oxidation process increases the solid solution oxygen level. This causes a large increase in strength at room temperature as compared with an increase in strength at higher temperatures.

(3) In the $\mathrm{V}-\mathrm{Zr}$ alloy system, the optimum content of zirconium is in the range of 0.3 $1.0 \%$.

(4) The strength of $\mathrm{V}-\mathrm{Zr}$ alloys changes considerably, by whether the alloy is internally oxidized under or above $1253 \mathrm{~K}\left(980^{\circ} \mathrm{C}\right)$. Namely, the strength of specimens internally oxidized at temperatures above $1253 \mathrm{~K}\left(980^{\circ} \mathrm{C}\right)$ are higher than those at lower temperatures. This phenomenon may be ascribed to the oxidation treatments which are performed at temperatures higher than the transformation temperature of $\mathrm{ZrO}_{2}$. This increment of strength may also be attributable to increase in the effective particle radius due to the expansion induced by the transformation of $\mathrm{ZrO}_{2}$ in the cooling process when the internal oxidation is carried out above the transformation temperature.

(5) The optimum internal oxidation time varies with the specimen shape, the dimension, and the diffusion constant at a given temperature.

\section{Acknowledgment}

The authors wish to thank Dr. Shoji Goto of Kyushu University for his instructive discussions and guidance. 


\section{REFERENCES}

(1) D. J. Roucliffe, R. M. Bonesteel and T. E. Tietz: Oxide Dispersion Strengthening (Metallurgical Society Conference Vol. 47) (1968), 741.

(2) R. M. Bonesteel, D. J. Roucliffe and T. E. Tietz: Proc. Int. Conf. on Strength of Metals and Alloys, Supplement to Trans. JIM, Vol. 9 (1968), p. 597.

(3) C. T. Liu, H. Inouye and R. W. Carpenter: Met. Trans., 4 (1973), 1839.

(4) R. L. Klueh and J. H. Devan: J. Less-Common Metals, 22 (1970), 389.

(5) E. N. Rhines: Trans. AIME, 137 (1940), 389.

(6) J. F. Elliott and M. Gleiser: Thermochemistry for
Steelmaking, Vol. 1, Addison-Wesley, (1960), p. 214.

(7) W. Rostoker: The Metallurgy of Vanadium, John Wiley and Sons, (1958), p. 83.

(8) R. W. Powers and M. V. Doyle: J. Appl. Phys., 30 (1959), 514.

(9) A. U. Seybolt: Oxide Dispersion Strengthening (Metallurgical Society Conference Vol. 47)(1968), p. 469.

(10) H. Fullman: Trans. AIME, 197 (1953), 447.

(11) C. Vercaemer, R. Geschier and A. Clauss: J. Less-Common Metals, 25 (1971), 199.

(12) H. Kayano: J. Japan Inst. Metals, 31 (1987), 310.

(13) H. Kayano, ibid., 318. 